\title{
ASSET CLASS DIVERSIFICATION AND DELEGATION OF RESPONSIBILITIES BETWEEN CENTRAL BANKS AND SOVEREIGN WEALTH FUNDS
}

\author{
Joshua Aizenman \\ Reuven Glick \\ Working Paper 16392 \\ http://www.nber.org/papers/w16392
NATIONAL BUREAU OF ECONOMIC RESEARCH
1050 Massachusetts Avenue
Cambridge, MA 02138
September 2010

The views expressed herein do not represent those of the Federal Reserve Bank of San Francisco, the Board of Governors of the Federal Reserve System, or the National Bureau of Economic Research.

NBER working papers are circulated for discussion and comment purposes. They have not been peerreviewed or been subject to the review by the NBER Board of Directors that accompanies official NBER publications.

(C) 2010 by Joshua Aizenman and Reuven Glick. All rights reserved. Short sections of text, not to exceed two paragraphs, may be quoted without explicit permission provided that full credit, including $\odot$ notice, is given to the source. 
Asset Class Diversification and Delegation of Responsibilities between Central Banks and Sovereign Wealth Funds

Joshua Aizenman and Reuven Glick

NBER Working Paper No. 16392

September 2010П5 HMLHO DFK⿴囗十

JEL No. E58,F15,F30,F33

\begin{abstract}
$\underline{\text { ABSTRACT }}$
This paper presents a model comparing the degree of asset class diversification abroad by a central bank and a sovereign wealth fund. We show that if the central bank manages its foreign asset holdings in order to meet balance of payments needs, particularly in reducing the probability of sudden stops in foreign capital inflows, it will place a high weight on holding safer foreign assets. In contrast, if the sovereign wealth fund, acting on behalf of the Treasury, maximizes the expected utility of a representative domestic agent, it will opt for relatively greater holding of more risky foreign assets. We also show how the diversification differences between the strategies of the bank and SWF are affected by the government's delegation of responsibilities and by various parameters of the economy, such as the volatility of equity returns and the total amount of public foreign assets available for management.
\end{abstract}

Joshua Aizenman

Department of Economics; E2

1156 High St.

University of California, Santa Cruz

Santa Cruz, CA 95064

and NBER

jaizen@ucsc.edu

Reuven Glick

Economic Research Department

Federal Reserve Bank of San Francisco

101 Market Street

San Francisco, CA 94105

reuven.Glick@sf.frb.org 


\section{Introduction}

In the aftermath of the financial crises of the late 1990s, many countries, particularly in emerging markets, have focused on the accumulation of official reserve assets. More recently, authorities have chosen to entrust more of their public foreign assets to sovereign wealth funds (SWFs). Private analysts put current sovereign wealth fund assets in the range of $\$ 2$ to 3 trillion or even higher. This amount is projected to grow to as much as $\$ 13$ trillion in the next ten years, an amount larger than the current global stock of foreign reserves of about $\$ 7$ trillion at year-end 2009. ${ }^{1}$

There are several reasons for the growth of sovereign wealth funds. First, commodity price increases have swelled the sovereign asset holdings of commodity-exporting countries where the public sector controls commodity exports or heavily taxes the revenues earned by private commodity exporters. In some cases, the assets accumulated by SWFs are used as a financial stabilizer if commodity prices fall and depress tax revenue declines. In other cases, the establishment of SWFs, such as Norway’s Government Pension Fund and Chile’s Pension Reserve Fund, was motivated by the desire to transform concentrated exposure of public assets to volatile commodity prices into a more balanced and diversified global exposure, thereby protecting the income of future generations. A second factor behind the growth of SWFs is a byproduct of efforts by many emerging market countries to accumulate large stockpiles of international reserves by running persistent current account surpluses, efforts that in many cases have lead reserve holdings to exceed what is needed for purely prudential reasons (see Aizenman 2008; Jeanne, 2007). The goal of diversifying these reserves into potentially higher-yielding assets has been pursued by transferring them from the control of the central bank to a SWF with the mandate to pursue financial strategies aiming at higher long-run returns. For example, China set up the China Investment Corporation (CIC) in 2007 to manage more aggressively a portion of the country’s more than $\$ 2$ trillion in public foreign assets. ${ }^{2}$

\footnotetext{
${ }^{1}$ Setser and Ziemba (2009) estimate that assets for major sovereign wealth funds totaled \$2.1 trillion at year-end 2008 (including \$700 billion in non-reserve assets of Russia and Saudi Arabia, but excluding roughly \$300 billion in non-reserve assets held by Hong Kong and other smaller funds). Truman (2008) estimates that SWFs managed just under \$3 trillion at the end of 2007 (he also identifies another \$2.3 billion under management by sovereign pension funds). His higher figure is partly attributable to higher estimates for funds managed by Abu Dhabi. Forecasts of future global SWF assets depend on a myriad of factors, including the magnitude of current account imbalances, central bank demand for greater liquidity, and changes in commodity prices and asset returns. See Aizenman and Glick (2009). More recent estimates yield a figure as high as \$3.3 trillion for 2010, excluding sovereign pension funds (Sovereign Wealth Fund Institute, 2011)

${ }^{2}$ Aizenman and Glick (2009) present statistical analysis supporting stylized facts about sovereign wealth funds (SWFs). Evidence is provided about the association of SWFs with a country's fuel export performance and current
} 
The optimal portfolio management of public foreign assets necessitates a balancing of the goals and investment strategies of the central bank with those of the SWF. In most countries, the SWF operates in a fundamentally different manner than the central bank which primarily holds official foreign reserves for precautionary reasons, as liquidity concerns necessitate a short investment horizon and low risk tolerance. Consequently, central banks generally invest their foreign exchange reserves conservatively in safe and marketable instruments that are readily available to monetary authorities to meet balance of payments needs, particularly in responding to sudden stops of foreign capital inflows. In contrast, SWFs typically seek to diversify foreign exchange assets and earn a higher return by investing in a broader range of asset classes, including longer-term government bonds, agency and asset-backed securities, corporate bonds, equities, commodities, real estate, derivatives, and foreign direct investment. ${ }^{3}$

The governance structure of central banks and sovereign wealth funds also differ. Central banks typically operate with some degree of independence, subject to achievement of specific monetary policy mandates, such as achieving an inflation or exchange rate target or maintaining financial stability. In contrast, SWFs usually operate with more explicit portfolio management goals, with their performance monitored more directly by government authorities. In Norway, for example, the Ministry of Finance is responsible for the management of the Government Pension Fund and has delegated responsibility for the operational management of the Fund's foreign assets to_Norges Bank Investment Management (NBIM), a separate part of Norway's central bank. Presently, the Chilean central bank appoints members of a Financial Committee which is responsible for making investment decisions and for the day-to-day running of the country's sovereign wealth fund. The Financial Committee reports to the Finance Minister who in turn reports to the country’s President.

The growth of assets under foreign sovereign management by both central banks and sovereign wealth funds has prompted concerns about their motivations, particularly as they have diversified more into equity and other privately-issued assets. In this paper we analyze the optimal patterns of portfolio diversification by a central bank and a sovereign wealth fund, given

account surpluses as well as the degree to which measures of SWF governance and transparency compare with national governance standards.

${ }^{3}$ There are exceptions to this division of goals. In some countries the central bank itself actively manages a portfolio with risky as well as safe assets. For example, Saudi Arabia's Monetary Authority manages the government's oil surpluses as well as riskier foreign investments without the vehicle of a standalone SWF. In China, the State Administration of Foreign Exchange (SAFE) has shifted its holdings towards riskier foreign investments, even with the establishment of the CIC. 
their specific policy mandates assigned by the government and the government's mode of delegating these policy responsibilities.

We start with a benchmark model with which we compare the optimal degree of diversification between safe and risky foreign assets depending on the authorities' utility function. We assume that the goal of the central bank is to maintain financial stability by solely focusing on the goal of reducing the probability of sudden capital stops. In contrast, we presume that the SWF, acting on behalf of the Treasury, maximizes the expected utility of a representative domestic agent. ${ }^{4}$ In this framework we show that the central bank's focus on financial stability implies that it will place a higher weight on limiting the downside risk of sudden stops than will the SWF. Consequently, the bank tends to bias its portfolio strategy towards holding more of the safe foreign asset, whereas the SWF opts for greater diversification towards riskier foreign assets. We also show how the diversification gap between the strategies of the bank and SWF is affected by various parameters of the economy, such as the volatility of equity returns and the total amount of public foreign assets available for management.

We follow with a more elaborate model of joint decision making in which we treat the Treasury as the dominant player and assume that it sets the total level of foreign assets managed by the central bank, but delegates to the central bank the responsibility for maintaining financial stability through the composition of its portfolio. Conditional on the actions of the central bank, the Treasury then decides what level of public foreign assets to entrust to the central bank for management as well as the composition of the residual share of the country's public foreign assets managed through the SWF. In these circumstances, we find that the assignment of the financial stability objective to the central bank tends to increase the gap between the optimal diversification patterns of the bank and the SWF, with the central bank specializing even more in holding safe assets so as to minimize the downside risk of sudden stop crises, while the SWF specializes more in holding foreign equity assets in its portfolio.

The plan of the paper is as follows. Section 2 presents the basic model of asset management by a central bank and sovereign wealth fund. Section 3 analyzes the implications of joint management through delegation of policy goals. Section 4 considers an extension to the intertemporal case. Section 5 presents conclusions.

\footnotetext{
${ }^{4}$ We abstract from the possibility that SWF investments may be driven by noneconomic considerations. Concerns that they may do has prompted a range of responses in potential recipient countries (see Aizenman and Glick, 2007).
} 


\section{The Base Model}

Central banks and sovereign wealth funds hold and manage public foreign assets typically accumulated through commodity export revenues or foreign exchange intervention in the face of current account surpluses. In this section we present a base model that explains how the authorities - either a central bank (CB) or a sovereign wealth fund (SWF) -- determine the diversification of a given initial level of public foreign asset holdings, $A$, between risk-free international reserves, $R$, and risky foreign equities $F$, such that $A=R+F$.

\section{$\underline{\text { Theoretical Specification }}$}

We start by treating the stock of foreign assets $A$ as exogenous, but later show how it can be determined endogenously. International reserves yield a gross risk-free interest rate $r$, whereas equity yields a stochastic return $r+e$, where $e$ is the equity premium. The realized value of public foreign assets at the end of the period, $A_{1}$, is given by

$$
A_{1}=r R+(r+e) F=r A+e F ; \quad 0 \leq F \leq A .
$$

The timing of the model is such that, after (i) determination of the portfolio composition $\{R, F\}$ at the beginning of the period and (ii) the realization of the equity return shock $e$ at the end of the period, there is a probability $\phi$ of a sudden stop crisis. The probability of a sudden stop depends negatively on the public sector's end-of-period total foreign assets, $A_{1}$, and positively on the exogenously given level of the country's aggregate foreign liabilities, $B$, such that $\phi=\phi\left[A_{1} / B\right] ; \quad \phi^{\prime}<0 .^{5}$ (In our notation we denote arguments of a function within square brackets.) Note that greater holdings of foreign risky asset can raise the probability of a sudden stop in the case of negative equity return shocks, i.e. $d \phi / d F=\phi^{\prime}\left[A_{1} / B\right](e / B)>0$ if $e<0$. In these circumstances, greater diversification towards foreign equities entails growing balance

\footnotetext{
${ }^{5}$ Foreign liabilities may be sovereign or private if the government serves as a lender of last resort in the event of a sudden stop crisis. We can motivate this setup by assuming in the background of the model that agents finance long-term investment via banks, while banks intermediate short-term deposits into longer term investment a la Diamond and Dybvig (1983). Financial integration implies exposure to sudden stops and capital flight shocks, which may drain the liquidity of the domestic banking system. A sudden stop entails costly pre-mature liquidation of long term investments, reducing thereby the output associated with these projects. The sudden stop probability can be derived endogenously by allowing for liquidity shocks $z$ to foreign borrowing (see Aizenman and Lee, 2007). If $z<$ $A_{1}$, the liquidity shock is financed by $A_{1}$, without disrupting long-term investment. If $z>A_{1}$, it leads to a sudden stop crisis associated with premature and costly liquidation of $z-A_{1}$ units of capital.
} 
sheet vulnerability because adverse equity return shocks reduce the value of foreign asset holdings, thereby raising the probability of sudden stops.

In the absence of a crisis, the foreign debt $B$ is repaid and (exogenous) end-of period output $Y_{1}$ is received. ${ }^{6}$ With the occurrence of a crisis, however, the debt is not repaid and there is a penalty $P$ associated with premature liquidation costs and possibly punitive actions by lenders that is assumed to be proportionate to end-of-period output and foreign assets ${ }^{7}$ :

$$
P=\tau\left(Y_{1}+A_{1}\right), 1 \geq \tau>0 .
$$

Hence consumption without (“ns) and with (“ss”) a sudden stop are, respectively,

$$
\begin{aligned}
& C_{1}^{n s}=Y_{1}+A_{1}-B, \\
& C_{1}^{s s}=Y_{1}+A_{1}-P .
\end{aligned}
$$

Agents are assumed to be risk averse, with utility function $U$. The SWF determines the portfolio allocation in order to maximize the expected utility of a representative domestic agent, $V_{s w}$ :

$$
V_{s w}=E\left[\left(1-\phi\left[A_{1} / B\right]\right) U\left[C_{1}^{n s}\right]+\left(\phi\left[A_{1} / B\right]\right) U\left[C_{1}^{s s}\right]\right]
$$

subject to the foreign asset accumulation relation (1), where $E$ is the expectation operator. Assuming an interior solution with diversification, the first-order condition determining $F$ for a given level of $A$ is:

$$
\begin{aligned}
d V_{s w} / d F=E[ & \left.(1-\phi) U^{\prime}\left[C_{1}^{n s}\right](e)+\phi U^{\prime}\left[C_{1}^{s s}\right] e(1-\tau)\right] \\
& -E\left[\phi^{\prime}\left[A_{1} / B\right](e / B)\left\{U\left[C_{1}^{n s}\right]-U\left[C_{1}^{s s}\right]\right\}\right]=0 .
\end{aligned}
$$

Rearranging terms,

$$
E[d U / d F]=E\left[\left(\phi^{\prime}\left[A_{1} / B\right]\right)(e / B)\left\{U\left[C_{1}^{n s}\right]-U\left[C_{1}^{s s}\right]\right\}\right]
$$

where

$$
E[d U / d F] \equiv E\left[(1-\phi) U^{\prime}\left[C_{1}^{n s}\right](e)+\phi U^{\prime}\left[C_{1}^{s s}\right] e(1-\tau)\right]
$$

\footnotetext{
${ }^{6}$ The model can be generalized by endogenizing the determination of foreign borrowing $B$. For example, in a twoperiod economy, where second-period output is subject to productivity shocks, the possibility that the country may default in the second period with a bad enough productivity shock implies that foreign borrowing is constrained by the condition that the cost of funds equals the expected return to lenders (see Aizenman and Marion, 2004). $Y_{1}$ might be expressed as a function of borrowing $B$ in this more general framework.

${ }^{7}$ This is a reduced form of the resources left following the premature liquidation of investments needed to finance deposits and capital flight. To simplify, we assume that that $A_{1}$ and $Y_{1}$ shrink at the same rate. The logic of our analysis continues to hold with different shrinkage rates of $A_{1}$ and $Y_{1}$, where the resources left would be $A_{1}\left(1-\tau_{A}\right)+Y_{1}\left(1-\tau_{Y}\right), 1 \geq \tau_{A}>0,1 \geq \tau_{Y}>0$.
} 
The left hand size of (4), $E[d U / d F]$, is the expected marginal benefit of diversification, i.e., the expected marginal utility valuation of the equity return premium associated with higher $F$, $d A_{1} / d F=e$. The right hand side of (4) is the expected marginal cost of diversification in the presence of a negative equity premium, i.e. the marginal increase in the probability of a sudden stop, $d \phi / d F=\phi^{\prime}\left[A_{1} / B\right](e / B)$, times the utility cost of lost consumption associated with a sudden stop, $U\left[C_{1}^{n s}\right]-U\left[C_{1}^{s s}\right] \cdot{ }^{8}$ Thus, the SWF increases its holdings of foreign equity assets to the level that balances the marginal increase in returns with the marginal cost of a rise in the probability of a sudden stop.

In contrast to a SWF, CB management is assumed to focus solely on maintaining financial stability, minimizing the probability of a crisis. The political economy of financial supervision may imply that there are benefits to delegating authority to an independent agency in order to overcome the temptation to relax supervision in "good” times (see Goodhart, 2008). Moreover, the financial crisis of 2008-09 illustrated that controlling inflation by itself does not alleviate the central bank's need to focus on financial stability as an independent objective. ${ }^{9}$ Accordingly, we refrain from modeling the determination of inflation and abstract from other possible central bank objectives, such targeting inflation under a flexible exchange rate regime. ${ }^{10}$ Instead, we simplify by specifying the CB's objective function as minimization of the expected probability of a sudden stop

$$
V_{c b}=E\left[\phi\left[A_{1} / B\right]\right] .
$$

Consequently, the first-order condition from maximizing (5) with respect to the CB's level of foreign equities $F$, while subject to (1), is

$$
d V_{c b} / d F=E\left[-\phi^{\prime}\left[A_{1} / B\right](e / B)\right]=0 .
$$

That is, the central bank increases its foreign equity assets to a level that minimizes the probability of a sudden stop by setting its marginal impact on the probability to zero.

\footnotetext{
${ }^{8}$ Note also that the utility cost is positive as long as $\left(A_{1}+Y_{1}\right) \tau>B$, i.e. the penalty costs are greater than the foregone foreign borrowing obligation.

${ }^{9}$ See Nier (2009) for further discussion and literature overview of the importance of financial stability among the objectives of the central bank.

10 The post-crisis resumption of large financial inflows to emerging markets provides another impetus for focusing on financial stability as the main objective of central banks in affected countries. We also do not model deeper reasons for our assignment of objectives, such as a possible bias towards nominating a conservative central bank governor with a narrower policy focus than the representative agent (see Rogoff, 1985; Walsh, 1995; Obstfeld, 1996; and Aizenman and Glick, 2008).
} 
Comparing the first-order condition for optimal portfolio diversification by the SWF, (4), to that for the $\mathrm{CB},(6)$, reveals that the $\mathrm{CB}$ ignores the possible expected gains to domestic agents induced by diversification in the presence of a positive equity premium. Instead, the CB minimizes the downside risk associated with adverse equity shocks, recognizing that such shocks would increase the leverage ratio $B / A_{1}$ at a rate proportionate to the equity portfolio share (since (1) implies $\left.A_{1} / A=r+e(F / A)\right)$, thereby increasing the probability of sudden stops in bad times. ${ }^{11}$ This suggests that the CB will opt for much less diversification into foreign equities than the SWF.

\section{$\underline{\text { Simulation Results }}$}

Further insight into the diversification patterns of the CB and SWF is gained by considering a simple simulation, with parameter values chosen to illustrate the challenges facing East Asian and commodity exporter countries, accumulating significant foreign assets at levels that frequently exceed their external liabilities, while also exposed to the risk of debilitating sudden stops and capital flight crises. We assume CRRA utility where the relative risk aversion parameter $\beta$ has a typical value of 2 . The equity premium $e$ equals an expected equity premium $\varepsilon$ plus an equity-return shock $\delta$ that takes on two values, either $\bar{\delta}$ or $-\bar{\delta}$, each with probability one half, implying mean value 0 and standard deviation $\sigma_{\delta}=\bar{\delta}$. We assume a gross safe interest return $r$ of unity and an expected equity premium of $5 \%$, i.e. $r=1, \varepsilon=0.05 .{ }^{12}$ We normalize initial output to $Y=1$, initial foreign assets $A$ to 0.5 ., and foreign borrowing $B$ to 0.5 . The experiences of Korea, Chile, and other emerging markets with ratios of foreign borrowing to GDP around 50\% and ratios of foreign reserve holdings to foreign borrowing fluctuating around $100 \%$ suggest that these parameter values are reasonable benchmarks. ${ }^{13}$ We assume a sudden stop crisis penalty $(\tau$ ) of $20 \%$, in line with the range of $10-20 \%$ reported by Hutchison and Noy (2006). Lastly, we specify the probability of a sudden stop as a polynomial function, $\phi\left(A_{1} / B\right)=\left(B /\left(A_{1}+B\right)\right)^{h} /\left[\left(B /\left(A_{1}+B\right)\right)^{h}+n\right]$ where the parameter values $h=4$ and $n=0.25$ are chosen to generate reasonable variations in the probability of sudden stops and changes in the composition of asset holdings as we vary other parameters in the simulation.

\footnotetext{
${ }^{11}$ Note $B / A_{1}$ is proportional to $A / A_{1}$ since $B / A_{1}=(B / A)\left(A / A_{1}\right)$ and $B / A$ is constant.

${ }^{12}$ Assuming a small positive net interest return affects the result trivially.

${ }^{13}$ See Chilean External Debt (2009, Chart 8) for details of Chile's experience and Jeong (2009) for an overview of Korea's experience.
} 
The left panel of Figure 1 plots the optimal share of foreign equities in a portfolio managed by the SWF (top curve) and the CB (bottom curve), each as a function of volatility $\bar{\delta}$, for our base case with $A=0.5 .{ }^{14}$ Observe that a lower return volatility $\bar{\delta}$ raises the optimal share of foreign holdings, $F / A$, for both a central bank and a sovereign wealth fund. In addition, because of the difference in preferences, the sovereign wealth fund holds more equities for any given level of volatility than does the central bank. To illustrate, for $\bar{\delta}=0.3$ (depicted by the vertical line), the SWF's equity share in its portfolio, $F / A$, is $100 \%$ (point a), whereas the CB opts for a much lower equity share, about $33 \%$ (point b). ${ }^{15}$

Changes in parameter values affect the optimal composition of each institution's portfolio. For example, a higher level of volatility in equity returns, say $\bar{\delta}=0.4$, induces both institutions to reduce their foreign equity holding. The SWF would reduce its equity investment from $100 \%$ of its portfolio to about $94 \%$, whereas the more conservative CB reduces its portfolio share of equities by a relatively greater amount, from about $33 \%$ to $18 \%$. As another example, a lower degree of risk aversion, i.e. lower $\beta$, shifts both schedules up (not shown), implying that the share of equity assets held by both the CB and the SWF is higher for any given level of volatility.

Our framework also can be applied to understand the effects of growing foreign public asset holdings on portfolio decisions. The right panel of Figure 1 illustrates the effects of the initial size of the asset base on diversification choices, by doubling $A$ from 0.5 to 1 . As can be observed, the higher level of public assets reduces the relative demand for foreign equities, i.e., the curves plotting the association between $F / A$ and volatility both shift down and to the left for any given level of $\bar{\delta}$. In this example, higher A has a relatively small effect on the CB's demand for equities: for equity return volatility $\bar{\delta}=0.3$ and $A=0.5$, equity demand was 33\% of A (point $\mathrm{b}$ in the left hand panel), while for $A=1$, this demand declines to $18 \%$ (point b' in the right hand panel). In contrast, a higher $A$ induces a more sizable decline in the SWF's equity demand, from a portfolio share of $100 \%$ (at point a in the left panel of Figure 1) to $48 \%$ (at point a' in the right panel of Figure 1). Thus, higher foreign asset base induces an increase in the absolute demand for foreign equities by the CB, but by an amount smaller than the increase in total foreign assets, implying a decline in the foreign equity share of the CB's portfolio.

\footnotetext{
${ }^{14}$ More specifically, these curves reflect the locus of points satisfying (3) and (6), respectively.

${ }^{15}$ We assume that the SWF is prohibited from borrowing, hence its equity position is maximized at $100 \%$.
} 
In the previous examples, for a reasonable range of variation in the volatility of equity returns, both institutions are diversified and hold both the risky and the safe foreign asset. In many countries, however, with both a sovereign wealth fund and a central bank, the two institutions specialize their portfolio investment, with the sovereign wealth fund holding only risky assets and the central bank holding (almost) only safe foreign assets. We illustrate this case in Figure 2, where the combination of assuming a lower crisis penalty ( $\tau=0.1$ ), lower foreign debt holdings $(B=0.4)$, and higher equity return volatility $(\bar{\delta}=0.4)$ induces the SWF to specialize totally into holding only foreign equity assets $(F / A=1)$, while the $C B$ chooses to allocate more than $90 \%$ of its assets into safe foreign reserves. Our analysis suggests that for a country without a SWF initially, a rising foreign asset base A may increase the opportunity cost associated with the limited portfolio diversification of the CB sufficiently to induce the authorities to establish a SWF, acting as an agent for the Treasury in pursuit of greater returns. ${ }^{16}$

We next turn to analysis of the comparative statics implications for the probability of sudden stops. We begin by analyzing how the size of the initial public asset position $A$ affects the probability of a sudden stops for fully specialized institutions, i.e. for a sovereign wealth fund investing only in risky foreign assets $(F / A=1)$ and for a central bank investing only in safe assets $(F / A=0)$.

Figure 3, left panel, plots the probability of crisis as a function of the foreign asset position $A$, for the case where all assets are allocated to equities. The lower curve, $\phi_{l}$, depicts the crisis probability relation when the realized equity shock is positive, with a realized value of $\delta=0.3$. The top curve, $\phi_{h}$, depicts the crisis probability relation when the equity shock is negative, with a value of $\delta=-0.3$. The other parameters are set at the same values as in the benchmark case presented in Figure 1.

Observe that both curves are negatively sloped, as greater foreign asset holdings (relative to foreign borrowing) imply a lower probability of a sudden stop. ${ }^{17}$ The $\phi_{h}$ curve lies everywhere above the $\phi_{l}$ curve because for a given initial foreign asset holdings, a negative shock results in a greater decline in the asset position, resulting in a higher probability of a crisis. The bold curve, $\phi_{e}$, is the expected crisis probability (calculated as a weighted average).

\footnotetext{
${ }^{16}$ This is consistent with the finding reported by Aizenman and Glick (2009) that older sovereign wealth funds not only have relatively high asset-to-GDP ratios, they also have relatively low foreign reserve/GDP ratios compared with more newly established funds.

${ }^{17}$ Recall that foreign borrowing is treated as exogenous throughout our analysis.
} 
The right panel of Figure 3 describes the effect on the crisis probability for an institution, such as a central bank, holding only safe reserves. In this case the probability of a sudden stop still depends negatively on the level of public assets, but there is no exposure to equity return shocks. Thus greater diversification into equities increases exposure to equity shocks, with a second-order magnitude effect on the expected probability of a crisis. In comparison, an institution such as a central bank that opts for a much lower diversification into equities, thereby reduces the downside risk associated with the exposure to bad realizations of equity return shocks.

How does the probability of a sudden stop depend on changes in the volatility of returns? Figure 4 plots the association between the equity shock realization $\delta$ and the sudden stop probability $\phi$ for the CB (dotted line) and SWF (bold line), given the optimal equity share $F$ chosen by each institution when $\bar{\delta}=0.3, A=0.5$, and all other parameters are the same as in the benchmark case depicted in Figure 1. More specifically, these relations are determined by first determining the institution's optimal $F$ conditional on $\bar{\delta}=0.3$, call it $F^{*}$ (which equals $100 \%$ of $A$ for the SWF and 33\% for the CB; see Figure 1, left panel), and then calculating the implied value of end-of-period assets $A_{1}, A_{1}=r A+e F^{*}$ and hence the crisis probability $\phi=\phi\left[A_{1} / B\right]$ for varying realizations of the equity premium $e=\varepsilon+\delta$, in turn corresponding to different realizations of $\delta$ (not necessarily equal to $\bar{\delta}$ or $-\bar{\delta}$ ).

The negative slopes of the curves plotted in Figure 4 indicate that more positive return realizations imply higher end-of-period asset holdings and a lower probability of sudden stop for both the CB and SWF. Observe as well that the limited diversification strategy pursued by the CB results in a relatively low probability of sudden stops, less than 0.065 , for the entire range of equity return shocks shown (-0.4 to 0.4$)$. In contrast, the greater holdings of risky foreign equities by the SWF expose the economy to the greater downside risk of a sudden stop in bad times, e.g. for a $\delta$ realization of -0.4 , the probability of a crisis is about 0.13 , twice as high as the probability for the CB for the same magnitude realization. This analysis implies that the central bank's diversification strategy tends to be relatively more resilient to unanticipated returns by maintaining a relatively low probability of sudden stop for a wide range of possible shocks. This suggests why it can be advantageous to assign portfolio management independence to the CB in order to limit the probability of sudden stops. However, these gains come at the opportunity cost of lost returns on foreign assets, which rise with the volume of funds under management. 
To summarize, the central bank's focus on financial stability implies that its portfolio share of risky foreign assets is lower and is less sensitive to changes in return volatility and in size than is a sovereign wealth fund.

\section{Delegation of Financial Stability Objective to Central Bank}

This section extends the base model, recognizing the possibility that the central bank has a comparative advantage in avoiding sudden stops and maintaining financial stability, whereas the SWF has a comparative advantage in managing risky portfolios. We continue to assume that the initial total foreign assets of the public sector $A$, and aggregate foreign borrowings $B$ are exogenously determined. But we now treat the Treasury as the dominant decision maker, determining the split of the given level of public foreign assets $A$ between the management of the SWF and the CB.

Each entity manages its own portfolio of foreign reserves and equities. Denote by $A_{c b}, A_{s w}$ the initial assets designated for management by the SWF and CB, respectively, such that $A=A_{c b}+A_{s w}$. Note that if $A$ is given and the Treasury determines $A_{c b}$, then $A_{s w}$ is determined as well.

The CB diversifies its portfolio between foreign reserves $\left(R_{c b}\right)$ and foreign equities $\left(F_{c b}\right)$, given its total initial asset holdings $A_{c b}=R_{c b}+F_{c b}$, implying that the realized value of assets under the CB's management at the end of the period, $A_{1, c b}$, is

$$
A_{1, c b}=r R_{c b}+(r+e) F_{c b}=r A_{c b}+e F_{c b} ; \quad 0 \leq F_{c b} \leq A_{c b} .
$$

As before, $r$ is the (gross) risk-free rate and $e=\varepsilon+\delta$ is the stochastic equity premium for investment in risky assets by the central bank, with $\varepsilon$ the expected equity premium and $\delta$ a mean-zero equity-return shock.

The SWF is assumed to have a comparative advantage in active management of the external portfolio, resulting in a higher expected equity premium $\varepsilon_{s w}, \varepsilon_{s w} \geq \varepsilon$, for any given volatility $\delta$. This reflects the possibility that the CB diversifies by passive portfolio investment channels (such as investing in broad and relatively liquid foreign stock indexes), whereas the SWF diversifies by more active portfolio management, including foreign direct investment, etc. possibly offering higher expected returns. Accordingly, the realized value of assets under SWF management at the end of the period is $A_{1, s w}$ :

$$
A_{1, s w}=r\left(A-A_{c b}\right)+e_{s w} F_{s w} ; \quad 0 \leq F_{s w} \leq A_{s w} \leq A
$$


As the CB deals directly with monitoring and supervising financial intermediation, we presume that the CB has a comparative advantage in reducing the probability of a financial crisis triggered by sudden stops. This may reflect both the lower liquidity of the SWF's investments as well as institutional frictions that may slow down the SWF's ability to mobilize resources. Specifically, for a given ratio of assets to foreign borrowing $A_{1} / B$, the CB's management results in a lower probability of sudden stops than would occur under SWF management, i.e. $\phi_{c b}\left[A_{1} / B\right]<\phi_{s w}\left[A_{1} / B\right]$ for all $A_{1} / B$, where $\phi_{c b}[],. \phi_{s w}[$. ]denote the sudden stop probability if assets are managed by the CB or a Treasury-controlled SWF, respectively.

The cost of delegating financial stability management to the CB is that, in case of need, only a fraction $q$ of the SWF's assets $A_{s w}$ would be available to the CB $(0 \leq q<1)$. Hence, under CB management $\phi_{c b}[\cdot]=\phi_{c b}\left[\left(A_{1, c b}+q A_{1, s w}\right) / B\right]$. For simplicity, we assume that $q=0$, implying $\phi_{c b}[]=.\phi_{c b}\left[A_{1, c b} / B\right]$. As before, the probability of a sudden stop is assumed to depend negatively on the ratio of the public sector's foreign assets to foreign liabilities, implying $\phi_{c b}^{\prime}<0$.

\subsection{Delegation and Diversification}

The diversification problem facing the CB is identical to the one described in Section 2, i.e. choose the level of foreign equity assets $F_{c b}$ that maximizes the objective function

$$
V_{c b}=E\left[\left(1-\phi_{c b}\left[A_{1, c b} / B\right]\right) U\left[C_{c b}\right]+\left(\phi_{c b}\left[A_{1, c b} / B\right]\right) U\left[C_{c b}\left(1-\tau_{c b}\right)\right]\right]
$$

subject to the asset accumulation relation (1'), where $\phi$ is replaced with $\phi_{c b}$. We continue to treat the foreign debt overhang $B$ as given by assumption and note that $A_{c b}$ is exogenous to the CB's actions, since it is determined by the Treasury. An analogue to the first-order condition (6) holds:

$$
d V_{c b} / d F_{c b}=E\left[\left(-\phi_{c b}^{\prime}\left[A_{1, c b} / B\right]\right)(e / B)\right]=0 .
$$

As in the case without delegation, the CB sets policies that minimize the probability of sudden stops. Note that its optimal level of reserves, determined by condition (6'), implies that the expected equity premium evaluated by its impact on the probability of a sudden stop is zero.

The SWF's expected utility is akin to (2), modified by delegating the financial stability objective to the CB: 


$$
V_{s w}=E\left[\left(1-\hat{\phi}_{c b}\left[A_{1, c b} / B\right]\right) U\left[C_{1, s w}^{n s}\right]+\left(\hat{\phi}_{c b}\left[A_{1, c b} / B\right]\right) U\left[C_{1, s w}^{s s}\right]\right]
$$

where

$$
\begin{aligned}
& C_{1, s w}^{n s}=Y_{1}+A_{1, s w}-B, \\
& C_{1, s w}^{s s}=\left(Y_{1}+A_{1, s w}\right)(1-\tau)
\end{aligned}
$$

and $\hat{\phi}_{c b}$ is the probability of a sudden stop, conditioned on optimal CB policy as determined by $\left(6^{\prime}\right){ }^{18}$

The Treasury's problem is to determine, for a given initial level of total public foreign assets $A$, the optimal levels of the SWF's investment in equities $F_{s w}$ and the CB's initial assets $A_{c b}$ that maximize its expected utility (2”), subject to (1”). The first-order condition for optimal $F_{s w}$ holdings by the SWF, assuming an internal equilibrium (i.e., $0<F<A_{s w}$ ), is

$$
E\left[d U_{s w} / d F_{s w}\right] \equiv E\left[\left[\left(1-\hat{\phi}_{c b}\right) U^{\prime}\left[C_{1, s w}^{n s}\right]+\left(\hat{\phi}_{c b}\right) U^{\prime}\left[C_{1, s w}^{s s}\right](1-\tau)\right]\left(e_{s w}\right)\right]=0 .
$$

Comparing (4”) to (4), we infer that delegating financial stability policy to the CB implies that the SWF equates the expected marginal benefit of diversification, $E\left[d U_{s w} / d F_{s w}\right]$, to zero, instead of, as in the no delegation case, equating it to the expected cost of increasing the probability of a sudden stop. Note also that condition (4”) implies that in a SWF's equilibrium, the expected marginal utility associated with the equity premium is zero.

The Treasury also determines the CB's initial foreign assets, $A_{c b}$, with the SWF managing the remainder $A_{s w}=A-A_{c b}$. The discussion in the previous section suggests that an increase in $A$ should lead to greater asset allocation by the Treasury to the SWF in order to secure higher returns. This holds trivially as the probability of sudden stop, $\hat{\phi}_{c b}$, approaches zero.

\footnotetext{
${ }^{18}$ To derive $\hat{\phi}_{c b}$, first note that (6') yields an expression for $F_{c b}$ as an implicit function of $A_{c b}$, as well as $B$ and $e$ : $F_{c b}=\widehat{F}_{c b}\left[A_{c b} ; B, \varepsilon, \sigma_{e}\right]$, where $\partial \widehat{F}_{c b} / \partial A_{c b}>0$. Substituting $\widehat{F}_{c b}$ into $\phi$ gives $\phi_{c b}=\phi_{c b}\left[A_{1, c b} / B\right]$

$=\phi_{c b}\left[\left(r A_{c b}+\widehat{F}_{c b}\left[A_{c b}\right] e\right) / B\right] \equiv \hat{\phi}_{c b}\left[A_{c b} ; B\right]$, where for large enough $r$ and small enough $\sigma_{e}^{2}, E\left[\partial \hat{\phi}_{c b} / \partial A_{c b}\right]<0$. Note the latter follows from the approximation $E\left[\partial \hat{\phi}_{c b} / \partial A_{c b}\right]=E\left[\hat{\phi}_{c b}^{\prime}\left(r+e \partial F_{c b} / \partial A_{c b}\right)\right]$$$
\cong E\left[\left\{\hat{\phi}_{c b}^{\prime}[0]+\hat{\phi}_{c b}^{\prime \prime}[0] e\right\}\left(r+e\left(\partial F_{c b} / \partial A_{c b}\right)\right)\right]=\hat{\phi}_{c b}^{\prime}[0] r+\hat{\phi}_{c b}^{\prime \prime}[0] \sigma_{e}^{2}\left(\partial F_{c b} / \partial A_{c b}\right) \text {. }
$$ 
More formally, the first-order condition determining $A_{c b}$ is:

$$
\begin{aligned}
d V_{s w} / d A_{c b}=E & {\left[\left(\left(1-\hat{\phi}_{c b}\right)\left(-U^{\prime}\left[C_{1, s w}^{n s}\right]\right)+\left(\hat{\phi}_{c b}\right)\left(-U^{\prime}\left[C_{1, s w}^{s s}\right]\right)(1-\tau)\right)\left(r+e \widehat{F}_{c b}^{\prime}\right)\right] } \\
& -E\left[\left(\hat{\phi}_{c b}^{\prime}\left(\left(r+e \widehat{F}_{c b}^{\prime}\right) / B\right)\left\{U\left[C_{1, s w}^{n s}\right]-U\left[C_{1, s w}^{s s}\right]\right\}\right)\right]=0 .
\end{aligned}
$$

or

$$
E\left[d U / d A_{c b}\right]=E\left[-\hat{\phi}^{\prime}{ }_{c b} e\left(\widehat{F}^{\prime}{ }_{c b} / B\right)\left\{U\left[C_{1, s w}^{n s}\right]-U\left[C_{1, s w}^{s s}\right]\right\}\right]=0
$$

where

$$
E\left[d U / d A_{c b}\right] \equiv E\left[\left(1-\hat{\phi}_{c b}\right) U^{\prime}\left[C_{1, s w}^{n s}\right]+\left(\hat{\phi}_{c b}\right) U^{\prime}\left[C_{1, s w}^{s s}\right](1-\tau)\left(r+e \widehat{F}^{\prime}{ }_{c b}\right)\right]
$$

and $\widehat{F}_{c b}^{\prime}$ is the marginal impact of an increase in initial foreign assets $A_{c b}$ on the CB's optimal foreign equity holdings. ${ }^{19}$ Thus the Treasury allocates more initial foreign assets to the central bank up to the point that the expected marginal benefit from doing so, $E\left[d U / d A_{c b}\right]$, equals the marginal increase in the probability of a sudden stop, $d \phi_{c b} / d F_{c b}=-\hat{\phi}_{c b}^{\prime} e\left(\widehat{F}_{c b}^{\prime} / B\right)$, times the utility cost of a sudden stop, $U\left[C_{1, s w}^{n s}\right]-U\left[C_{1, s w}^{s s}\right]$.

\subsection{Delegation and Welfare}

In this section we analyze the welfare gains to the policy of delegating foreign asset management to the CB and SWF as described above. The representative consumer cares only about utility associated with the net resources available for household consumption. (We presume that the compensation of the $\mathrm{CB}, C_{c b}$, and of the SWF's managers are negligible portions of GDP, and hence too small to impact consumption per capita.) Therefore, for the representative consumer, consumption is determined by the total sum of the assets accumulated by both agencies, $A=A_{s w}+A_{c b}$.

The consumer's expected utility is

$$
V=E\left[(1-\phi) U\left[C^{n s}\right]+\phi U\left[C^{s s}\right]\right] \text {, }
$$

where

\footnotetext{
${ }^{19}$ As noted in the previous footnote, (6') yields an expression for $F_{c b}$ as an implicit function of $A_{c b}$, as well as $B$ and $e: F_{c b}=\widehat{F}_{c b}\left[A_{c b} ; B, e_{\delta}\right]$.
} 


$$
\begin{aligned}
& C_{1}^{n s}=Y_{1}+A_{1, c b}+A_{1, s w}-B=Y_{1}+r A+e F_{c b}+e_{s w} F_{s w}-B \\
& C_{1}^{s s}=\left(Y_{1}+A_{1, c b}+A_{1, s w}\right)(1-\tau)=\left(Y_{1}+r A+e F_{c b}+e_{s w} F_{s w}\right)(1-\tau) .
\end{aligned}
$$

It is assumed that the default penalty is large enough such that a sudden stop is associated with lower consumption, i.e. $C^{n s}>C^{s s}$. The following claim follows:

Claim: Assume that (i) the CB has a comparative advantage in prudential regulation, as defined by the relation $\phi_{c b}=(1-b) \phi_{s w}, \quad 0 \leq b \leq 1$, where the parameter $b$ measures the extent to which the probability of a sudden stop is lower with the CB than with the SWF, and (ii) the SWF has an advantage in portfolio management in the form of a higher expected return to foreign equity investment, i.e. $\varepsilon_{s w}>\varepsilon$. Then the direct gains from delegation increase with the comparative advantage of each agency.

Proof: The claim flows from the observation that $d V / d b>0, d V / d\left(\varepsilon_{s w}-\varepsilon\right)>0$, i.e. consumer utility is increasing in the magnitude of the CB's comparative advantage and in the SWF's investment equity premium. ${ }^{20}$

Intuitively, the case for delegation is stronger the greater are the efficiency gains associated with allowing each agency to focus on its comparative advantage. Quite trivially, in the absence of any distortions and gains from the proper division of management objective among the CB and the SWF, delegation could be welfare reducing, since the CB's preferences are biased towards "safety first" relative to that of the representative consumer. Henceforth we assume that the gain from the division of goals is powerful enough to induce higher expected utility under delegation.

We close this section with an example illustrating the welfare gains associated with delegation. The example is based on the simulation described in the right hand side panel of Figure 1, with $A=1$ and $\varepsilon=0.05$, where in the absence of delegation the optimal level of $F$ was 0.48 , i.e., the authorities allocated $48 \%$ of foreign assets into equities. This amount of diversification implies that the equity return in the bad state is -25\% (since $e_{l}=\varepsilon-\bar{\delta}=.05-.3=-0.25$, where $e_{l}$ denotes the equity return in the low state), and the sudden stop probability, $\phi_{\delta=-\bar{\delta}}$, is $6.5 \%$.

\footnotetext{
20 These results can be established by noting that $d V / d b=E\left[\phi_{s w}\left\{U\left[C^{n s}\right]-U\left[C^{s s}\right]\right\}\right]>0$ and $d V / d \varepsilon_{s w}=E\left[(1-\phi) U_{C^{n s}}^{\prime}+\phi(1-\tau) U_{C^{s s}}^{\prime}+\left(d \phi / d \varepsilon_{s w}\right)(1-\phi)\left\{U\left[C^{n s}\right]-U\left[C^{s s}\right]\right\}\right]>0$.
} 
Suppose that delegation induces gains from the division of goals. In this spirit, we assume that delegating risk monitoring to the CB reduces the probability of sudden stop for any given amount of diversification by $40 \%$, implying $\phi_{c b}=(1-b) \phi_{s w}$, with $b=0.4$. We also assume that the expected equity premium earned by the SWF over the central bank is $2 \%$, so that $\varepsilon_{s w}=\varepsilon+0.02=0.07$. Lastly, assume that with the delegation of prudential management to the $\mathrm{CB}$, the authorities (i) allocate to the $\mathrm{CB}$ the same amount of foreign assets that were put into reserves in the absence of delegation (i.e. $A_{c b}=0.52 \cdot 1$ ) and direct the CB to invest all these assets in reserves and (ii) allocate to the SWF the remaining assets, $0.48 \cdot 1$, all to be invested in equities (i.e. $\left.F_{s w}=A-A_{c b}=0.48\right){ }^{21}$ It can be shown that, in the presence of the gains from the division of management described above, delegation leads to welfare gains similar to increasing the initial endowment by about $0.4 \%$, reducing the probability of sudden stop in the bad state of nature from $6.5 \%$ to about $4 \% .^{22}$

\section{Extending the Model to the Intertemporal Case}

In this section we extend the model to the intertemporal case, where the authorities maximize the two-period expected utility function

$$
V=U[C]+\frac{1}{1+\rho} E\left[U\left[C_{1}\right]\right]
$$

with $C, C_{1}$ denoting consumption in the initial and subsequent periods, respectively, and $\rho$ the intertemporal rate of time preference. This extension allows us to derive the total size of the public foreign asset portfolio $(A)$ endogenously. Under delegation, policies are determined by the CB and SWF as described in Section 3, where the representative consumer cares only about the net resources supporting consumption.

The initial period consumption, $C$, is output $Y$, net of "investment” in foreign reserves $R$ and foreign equity assets $F$ (we abstract from the effect of past foreign borrowing, the "debt overhang," on income flows in the initial period). Next-period consumption, $C_{1}$, depends on asset returns and the costs of a possible sudden stop as well as repayment of the debt overhang $B$.

\footnotetext{
${ }^{21}$ It can be verified that for $A_{c b}=0.21$, the CB has a strong bias towards foreign reserves. Thus, the CB would opt to invest more in reserves even in the absence of the authorities' directive.

22 This result is obtained by calculating the expected utility gain, deflating it by the marginal utility evaluated for a zero equity return shock. This ratio provides the expected utility gain in terms of the equivalent rise in the initial endowment $Y_{1}$. Deflating this gain by the initial endowment translates the welfare gain to the equivalent percentage increase in the initial output, $Y_{1}$.
} 
As before, foreign reserves earn a gross return of $r$ and equity assets a return of $r+e$, where the equity premium $e$ equals an expected equity premium $\varepsilon$ plus a zero-mean equity-return shock $\delta$. Hence, the intertemporal consumption conditions are:

$$
\begin{aligned}
& C=Y-R-F \\
& C_{1}=\left\{\begin{array}{l}
C_{1}^{n s}=Y_{1}+r R+(r+\varepsilon+\delta) F-B \\
C_{1}^{s s}=Y_{1}+r R+(r+\varepsilon+\delta) F(1-\tau)
\end{array}\right\}
\end{aligned}
$$

where next-period consumption without and with a sudden stop are denoted by "ns and "ss", respectively. We assume that the default penalty is large enough such that a sudden stop is associated with lower consumption, i.e. $C_{1}^{n s}>C_{1}^{s s}$. Accordingly, the representative consumer's expected utility is

$$
V=U[Y-R-F]+\frac{1}{1+\rho} E\left[(1-\phi) U\left[C_{1}^{n s}\right]+\phi U\left[C_{1}^{s s}\right]\right] .
$$

Applying the logic of section 3, with delegation such that $\phi=\phi_{c b}$ the CB acts to maximize consumer expected utility by minimizing the probability of sudden stops. ${ }^{23}$ The optimal levels of reserves and foreign assets that achieve this goal are determined by the conditions $^{24}$

$$
\begin{aligned}
& d \phi / d R_{c b}=E\left[\phi_{c b}^{\prime}\left[A_{1, c b} / B\right]\right](r / B)=0 \\
& d \phi / d F_{c b}=E\left[\phi_{c b}^{\prime}\left[A_{1, c b} / B\right](r+e)\right]=0 .
\end{aligned}
$$

Note that in a diversified equilibrium, (12a) and (12b) jointly imply that the expected equity premium evaluated by its impact on the probability of sudden stop is zero:

$$
E\left[\phi_{c b}^{\prime}\left[A_{1, c b} / B\right](e / B)\right]=0 .
$$

The SWF takes as given $\hat{\phi}_{c b}$, the sudden stop probability conditioned on optimal CB behavior, and determines its equity position $F$ in a way akin to Section 3 . The optimality conditions for diversification by the SWF, i.e., holding positive levels of both $F$ and $R$, are ${ }^{25}$

\footnotetext{
${ }^{23}$ This follows trivially from the assumption that the CB's manager is paid a lump sum in good times, and only a fraction of it in sudden stops (possibly zero, losing his post).

${ }^{24}$ A sufficient condition for the central bank to hold both foreign equity as well as reserves is $\left.d \phi / d F_{c b}=E\left[\phi_{c b}^{\prime}\left[A_{1, c b} / B\right](r+e) / B\right)\right]_{F=0}<0$, i.e. adding foreign equity to the portfolio lowers the probability of a sudden stop.

${ }^{25}$ A sufficient condition for the SWF to hold reserves as well as foreign equity is if doing so increases expected utility evaluated at the optimal $F, \hat{F}_{s w}$, i.e.
} 


$$
\begin{aligned}
U^{\prime}(C) & =\frac{E\left[\left(r+e_{s w}\right)\left[\left(1-\hat{\phi}_{c b}\right) U^{\prime}\left[C_{1, s w}^{n s}\right]+\left(\hat{\phi}_{c b}\right) U^{\prime}\left[C_{1, s w}^{s s}\right](1-\tau)\right]\right]}{1+\rho} \\
U^{\prime}(C) & =\frac{r E\left[\left[\left(1-\hat{\phi}_{c b}\right) U^{\prime}\left[C_{1, s w}^{n s}\right]+\left(\hat{\phi}_{c b}\right) U^{\prime}\left[C_{1, s w}^{s s}\right](1-\tau)\right]\right]}{1+\rho} .
\end{aligned}
$$

Thus, in equilibrium the SWF equates current marginal utility to expected (discounted) future marginal utility. Note (14a) and (14b) imply that the expected marginal utility associated with the equity premium is zero:

$$
E\left[e_{s w}\left[\left(1-\hat{\phi}_{c b}\right) U^{\prime}\left[C_{1, s w}^{n s}\right]+\left(\hat{\phi}_{c b}\right) U^{\prime}\left[C_{1, s w}^{s s}\right](1-\tau)\right]\right]=0 .
$$

The equilibrium conditions above pin down the optimal levels of $F_{c b}, R_{c b}, F_{s w}, R_{s w}$. To illustrate, suppose that the configuration of parameter values is such that there is full division of management goals, with the CB holding only international reserves, and the SWF holding only equities, i.e. $F_{c b}=0, R_{s w}=0$. This implies that $A_{c b}=R_{c b}, A_{s w}=F_{s w}$ and hence $A=R_{c b}+F_{s w}$. Hence the determination of $R_{c b}$ and $F_{s w}$ pins down $A$, the overall level of foreign assets under public management.

To gain further insight we assume that the probability of a sudden stop follows a power function as specified in section 2, and that the risk-free real interest rate equals the subjective discount factor $(r=1+\rho)$. It can be shown that the central bank's demand for reserves increases with the debt overhang, equity return volatility, and the foreign equity held by the SWF, i.e. $R_{c b}=R_{c b}\left[B, \bar{\delta}, F_{s w}\right] ; R_{c b, B}^{\prime}>0, R_{c b, \bar{\delta}}^{\prime}>0, R_{c b, F_{s w}}^{\prime}>0$. The equity holdings of the SWF decline with a higher debt overhang and greater volatility of equity returns, and increase with the expected equity premium, i.e., $F_{s w}=F_{s w}\left[B, \bar{\delta}, \varepsilon_{s w}\right] ; F_{s w, B}^{\prime}<0, F_{s w, \bar{\delta}}^{\prime}<0, F_{s w, \varepsilon_{s w}}^{\prime}>0$.

What are the effects of changes in the exogenous parameters -- $B, \bar{\delta}, \varepsilon_{s w}--$ on total public foreign assets? In the case of an increase in $\varepsilon_{\text {sw }}$, we can infer that the effect is unambiguously positive: an increase in the expected equity premium leads to higher $F_{s w}\left(\right.$ since $F_{s w, s_{s w}}^{\prime}>0$ ),

$$
r E\left[\left(1-\hat{\phi}_{c b}\right) U^{\prime}\left[C_{1, s w}^{n s}\right]+\left(\hat{\phi}_{c b}\right) U^{\prime}\left[C_{1, s w}^{s s}\right](1-\tau)\right] /\left.(1+\rho)\right|_{\substack{F=\hat{S}_{W W} \\ R_{S w}=0}}>\left.U^{\prime}(C)\right|_{\substack{F=\hat{S}_{W W} \\ R_{S w}=0}}
$$

or, equivalently through use of the FOC for optimal $F$, (14a),

$$
E\left[\left\{\left(1-\hat{\phi}_{c b}\right) U^{\prime}\left[C_{1, s w}^{n s}\right]+\left(\hat{\phi}_{c b}\right) U^{\prime}\left[C_{1, s w}^{s s}\right](1-\tau)\right\} e_{s w}\right] /\left.(1+\rho)\right|_{\substack{F=\hat{F}_{S W} \\ R_{s w}=0}}>0 .
$$


which in turn leads to higher $R_{c b}$ (since $R_{c b, F_{S w}}^{\prime}>0$ ) as well. Intuitively, if the foreign equity return is higher, policymakers will want to increase the total stock of foreign assets $\left(A=R_{c b}+F_{s w}\right)$ under public management.

The effects of an increase in $\bar{\delta}$ or $B$ are ambiguous. For example, an increase in volatility $\bar{\delta}$ has the direct effect of reducing demand for holding risky foreign assets $F_{s w}$ (since $F_{s w, \bar{\delta}}^{\prime}<0$ ) which in turn indirectly reduces $R_{c b}$ as well (since $R_{c b, F_{s w}^{\prime}}^{\prime}>0$ ). But there is also the direct effect that leads to higher $R_{c b}$ in order to provide more insurance against sudden stops (since $R_{c b, \bar{\delta}}^{\prime}>0$ ). The overall sign depends on which effect dominates.

\section{Conclusions}

The optimal portfolio management of public foreign assets necessitates a balancing of returns and risks, where the latter reflect the risks of financial instability as well as the volatility of investment returns. In this paper we have presented a model with which we compare the optimal degree of diversification into safe foreign reserve assets and other higher-yielding, but risky, foreign assets by a central bank versus that of a sovereign wealth fund. We show that if the central bank manages its foreign assets with the objective of reducing the probability of sudden stops in foreign capital inflows, it will place a high weight on the downside risk of holding risky assets abroad and will tend to hold primarily safe foreign assets for precautionary purposes. In contrast, if the sovereign wealth fund, acting on behalf of the Treasury, operates with the objective of maximizing the expected utility of a representative domestic agent, it will opt for relatively greater holding of higher yielding, though riskier, foreign assets. We also show how the diversification differences between the strategies of the bank and SWF is affected by government's delegation of responsibilities and by various parameters of the economy, such as the volatility of equity returns and the total amount of public foreign assets available for management. In addition, we illustrate why it might be desirable for policymakers to delegate the objective of achieving financial stability to the central bank alone.

The global financial crisis of 2007-08 highlighted the importance of the precautionary purpose for holding international reserves by central banks. Moreover, the drop in global commodity prices and equity returns during the crisis reduced the supply of public foreign funds and dampened the relative appeal of investing abroad in risky assets by both central banks and sovereign wealth funds. If the volatility in financial markets remains high, monetary authorities 
may continue to place a high weight on holding more reserves as a means of minimizing the expected costs of sudden stop crises. Nevertheless, the resumption of global growth, particularly in emerging markets, appears to be restoring the attractiveness of foreign investment by sovereign wealth funds. Policymakers in these countries still must seek to balance the relative rewards to doing so against the gains to reducing the probability of financial instability. 


\section{References}

Aizenman, J. and R. Glick (2007), "Sovereign Wealth Funds: Stumbling Blocks or Stepping Stones to Financial Globalization?” Federal Reserve Bank of San Francisco Economic Letter, No 2007-38.

Aizenman, J. and R. Glick (2008), “Pegged Exchange Rate Regimes - A Trap?” Journal of Money, Credit and Banking, 40: 817 - 835.

Aizenman, J. and R. Glick (2009). "Sovereign Wealth Funds: Stylized Facts about their Determinants and Governance,” International Finance, 12:3: 351-386.

Aizenman J. and J. Lee (2007), “International Reserves: Precautionary versus Mercantilist Views, Theory and Evidence,” Open Economies Review, 18:191-214.

Aizenman, J. and N. Marion (2004), “International Reserve Holdings with Sovereign Risk and Costly Tax Collection,” Economic Journal 114: 569-591.

Chilean External Debt (2009). Bank of Chile, see website http://www.bcentral.cl/eng/publications/statistics/external-sector/pdf/externaldebt2009.pdf

Diamond D. and P. Dybvig (1983), “Bank runs, Liquidity and Deposit Insurance,” Journal of Political Economy, 91:401-419.

Goodhart, C. A.E. (2008), “Central Banks’ Function to Maintain Financial Stability: An Uncompleted Task,” Vox Research, June 24.

Hutchison, M. and I. Noy (2006), "Sudden stops and the Mexican wave: Currency crises, capital flow reversals and output loss in emerging markets," Journal of Development Economics, 79, no 1: $225-248$

Jeanne, O. (2007), “International Reserves in Emerging Market Countries: Too Much of a Good Thing?” Brookings Papers on Economic Activity 2007, no. 1: 1-79.

Jeong Y.S. (2009), “Analysis of Korea’s Debt Structure and Implications,” Samsung Economic Research Institute Quarterly (October): 43-50.

Nier, E. W. (2009), "Financial Stability Frameworks and the Role of Central Banks: Lessons from the Crisis,” IMF Working Paper No. 09/70, Washington, DC.

Obstfeld, M. (1996), “Models of Currency Crises with Self Fulfilling Features.” European Economic Review 40 (April): 1037-1048.

Rogoff, K. (1985), “The Optimal Degree of Commitment to an Intermediate Monetary Target,” Quarterly Journal of Economics, 1169-1189.

Sovereign Wealth Fund Institute (2011). “Sovereign Wealth Fund Rankings,” http://www.swfinstitute.org/fund-rankings. (accessed January 15, 2011). 
Truman, E. (2008), “A Blueprint for Sovereign Wealth Fund Best Practices,” Peterson Institute for International Economics, Policy Brief No. PB08-3, Washington DC.

Walsh, C. (1995), “Optimal Contracts for Central Bankers,” American Economic Review 85: 150-167. 
Figure 1. Equity returns volatility, foreign equity holdings, and foreign asset size
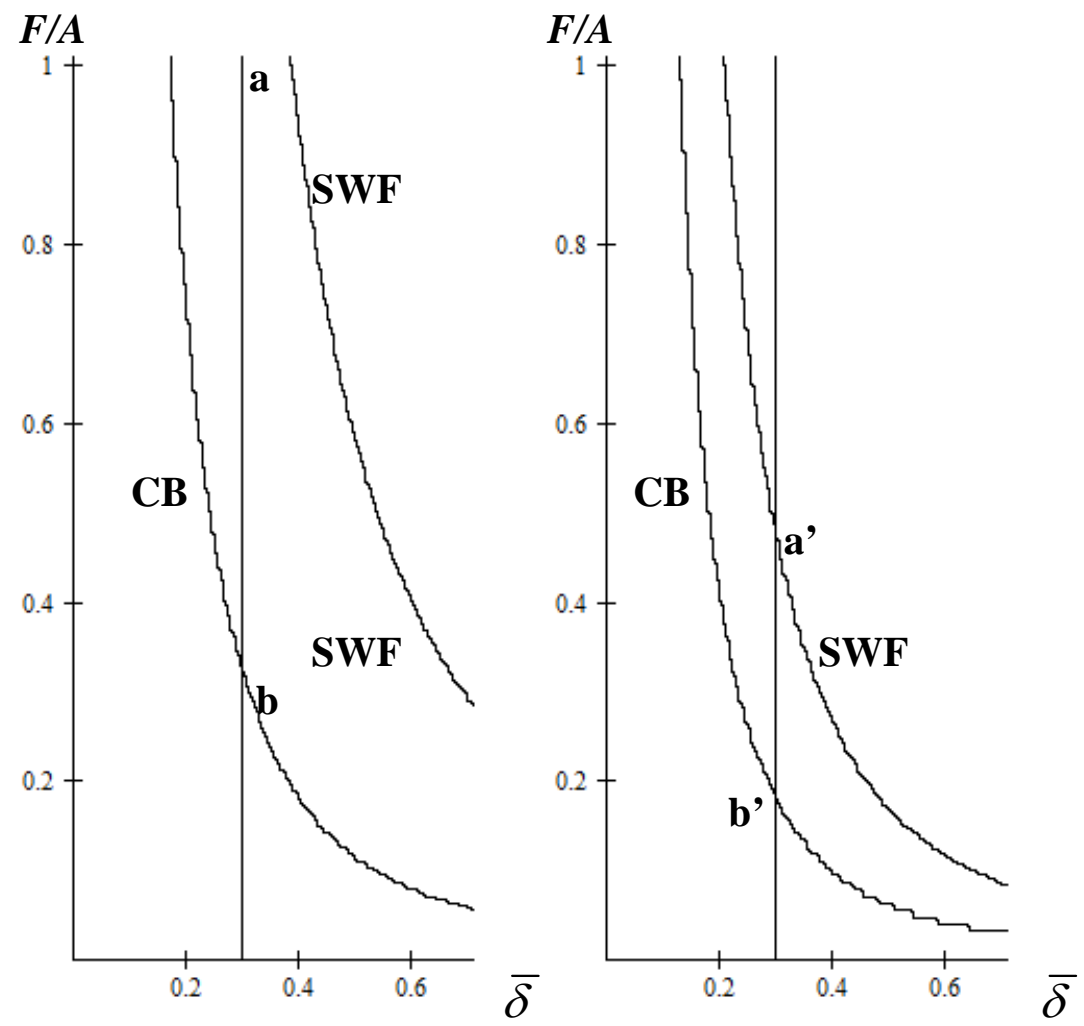

$$
A=0.5 \quad A=1
$$

Note: The bottom (top) curve describes asset diversification of the CB (SWF). The simulation assumes $U[C]=C^{1-\beta} /(1-\beta), \phi\left(A_{1} / B\right)=\left(B /\left(A_{1}+B\right)\right)^{h} /\left[\left(B /\left(A_{1}+B\right)\right)^{h}+n\right]$, the equity shock $\delta$ takes on two values, either $\bar{\delta}$ or $-\bar{\delta}$, and $r=1, \beta=2, Y_{1}=1$, $A=B=0.5, \varepsilon=0.05, \tau=0.2, h=4, n=0.25$. The left-hand and right-hand panels assume initial asset size levels $A$ of 0.5 and 1 , respectively. The vertical line corresponds to $\bar{\delta}=0.3$. 
Figure 2. Equity returns, volatility, and portfolio specialization patterns: an example

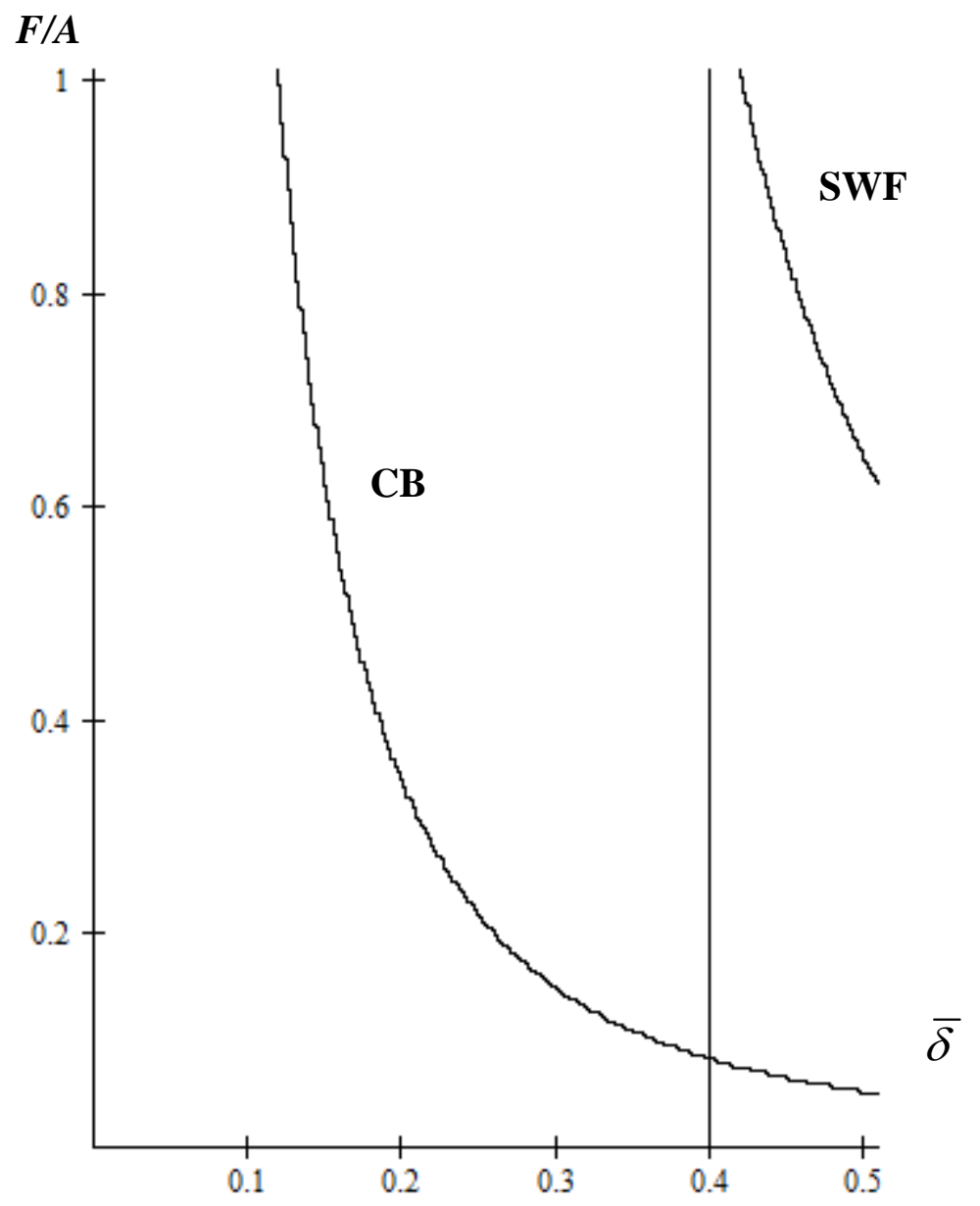

The simulation assumes the equity shock $\delta$ takes on two values, either $\bar{\delta}$ or $-\bar{\delta}$, and $r=1, \beta=2, Y_{1}=2, A=0.5, B=0.4, \varepsilon=0.05, \tau=0.1, h=6, n=0.25$. 
Figure 3: Sudden stop probabilities for varying initial total foreign asset holdings, with $F / A=1$ (left panel) and for $F / A=1$ (right panel).

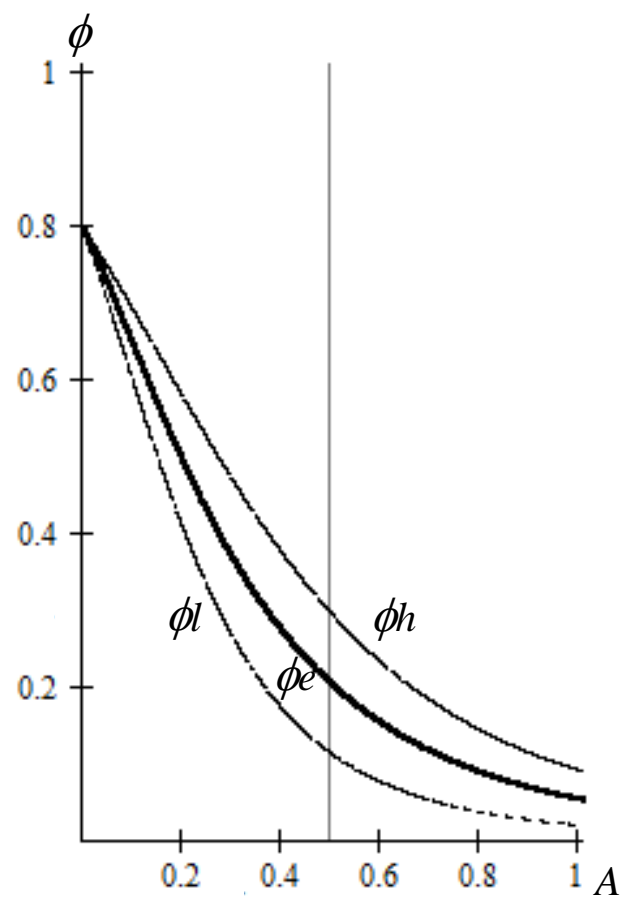

$F / A=1$

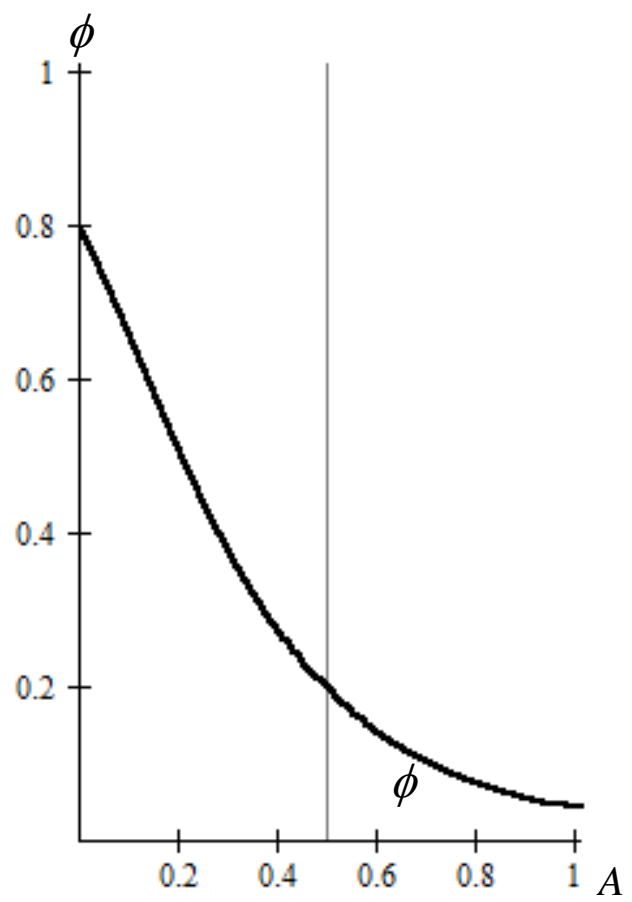

$F / A=0$

Note: In the left panel, the lower curve, $\phi_{l}$, is the crisis probability when the equity shock is positive, $\delta=0.3$; the top curve, $\phi_{h}$, is the crisis probability when the equity shock is negative, $\delta=-0.3$; and the bold curve, $\phi_{e}$, is the expected crisis probability. In the right panel the crisis probabilities are independent of equity shocks. The simulation assumes $U[C]=C^{1-\beta} /(1-\beta), \phi\left(A_{1} / B\right)=\left(B /\left(A_{1}+B\right)\right)^{h} /\left[\left(B /\left(A_{1}+B\right)\right)^{h}+n\right]$, and the equity shock takes on two values, either $\bar{\delta}$ or $-\bar{\delta}$. 
Figure 4. Probability of sudden stop for different equity-return shock realizations.

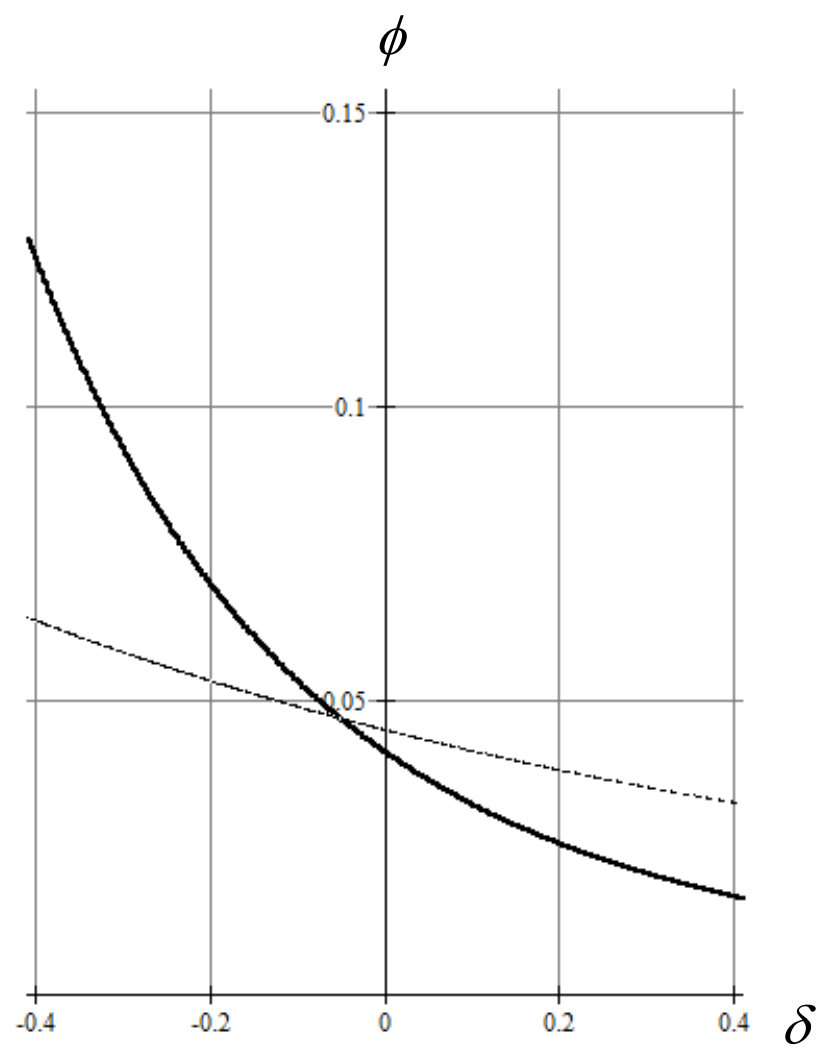

Note: The bold curve describes the sudden stop probability for $F / A=1$ (the SWF's optimal equity share for a volatility level $\bar{\delta}=0.3$ ), while the dotted curve shows the sudden stop probability for $F=0.33$ (the CB's optimal equity share for $\bar{\delta}=0.3$ ). The simulation assumes the parameters specified in Figure 1 , left panel $(A=0.5)$. 